\title{
Místicas españolas del Siglo de Oro en el Imperio Otomano: siete manuscritos árabes hallados en Alepo (Siria) ${ }^{7}$

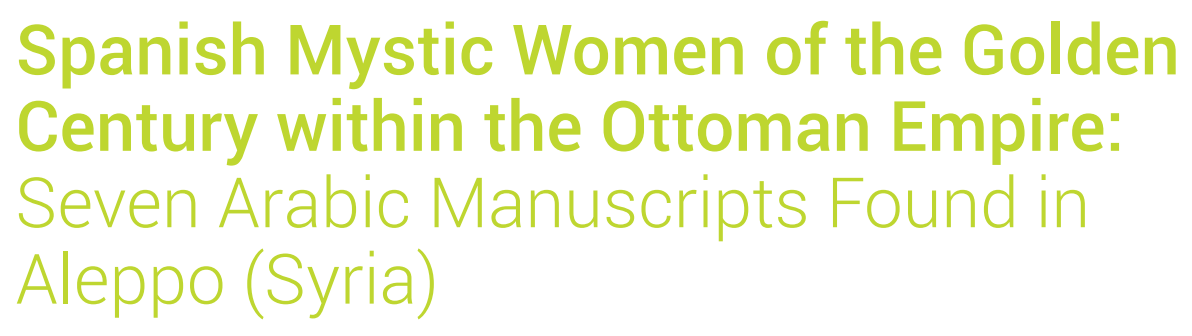

\section{Francisco del Río Sánchez ${ }^{2}$}

Universidad de Barcelona

Departamento de Filología Semítica

ESPAÑA

ffdelrio@ub.edu

[Hipogrifo, (issn: 2328-1308), 3.1, 2015, pp. 187-201]

Recibido: 07-05-2014 / Aceptado: 07-10-2014

DOI: http://dx.doi.org/10.13035/H.2015.03.01.12

Resumen. En el presente trabajo se da noticia de la existencia de siete códices conservados en tres diferentes bibliotecas o depósitos de manuscritos de la ciudad siria de Alepo (a saber, la biblioteca greco-católica o melquita, la colección de la Fundación Georges et Mathilde Salem y la biblioteca de los maronitas). Esos siete ejemplares contienen traducciones al árabe de varias obras de dos místicas españolas del Siglo de Oro: Teresa de Ávila y María de Ágreda. La historia de estas versiones árabes, realizadas en el corazón de las provincias árabes del imperio otomano, constituye un interesante objeto de estudio que está directamente relacionado con la manera en que, durante los siglos XVI-XVIII, se transmitieron hacia el Levante mediterráneo muchas obras compuestas en el Occidente europeo.

Palabras clave. Manuscritos, Imperio Otomano, traducciones árabes, mística.

1. Este trabajo se encuadra en el marco del Proyecto I+D FFI2011-25460/FILO.

2. Francisco del Río Sánchez es profesor titular del Departamento de Filología Semítica de la Universidad de Barcelona. Desde el año 2005 es el responsable de un proyecto de investigación centrado en la catalogación y la conservación del patrimonio manuscrito preservado en algunas bibliotecas privadas del norte de Siria. 
Abstract. This work reports on the existence of seven manuscripts conserved in three different collections of Aleppo (Syria): the Greek-Catholic/Melkite, the Georges and Mathilde Salem Foundation and the Maronite libraries. These seven copies contain the Arabic translations of some mystical works written by two mystic women of the Spanish Golden Century, Teresa de Ávila and María de Ágreda. The history of these Arabic versions, translated right in the heart of the Ottoman Arabic provinces, constitutes an interesting object of study that is directly linked with the manner in which many European Western works passed to the Mediterranean Levant during the 16th and 17th centuries.

Keywords. Manuscripts, Ottoman Empire, Arabic translations, Mysticism.

En las bibliotecas privadas de la República Árabe de Siria se conservan algunas interesantes copias manuscritas principalmente en árabe y en siríaco, algunas de las cuales se remontan incluso al siglo $X$ d. C. Estas colecciones de manuscritos, formadas a lo largo de los siglos gracias a donaciones de particulares (waqf) ${ }^{3}$, por medio de adquisiciones o por simple acumulación de volúmenes, contienen códices aún no catalogados de obras antiguas e inéditas de diferentes géneros, entre los que destacan la literatura, la poesía, las ciencias, la medicina, la magia, la filosofía, la teología y las diferentes obras de inspiración religiosa y el derecho. El número total de manuscritos conservados en estas instituciones no ha sido determinado con exactitud.

El hecho es que, a la hora de estudiar estos manuscritos, los investigadores únicamente podían servirse de simples inventarios o catálogos antiguos sin suficiente información acerca de sus contenidos. Esta carencia conllevaba otros efectos: el deterioro de las copias - que con frecuencia están mal conservadas- y el peligro de destrucción o desaparición, un peligro que se ha visto acentuado de modo trágico a causa de los acontecimientos que, a día de hoy, vive la República Árabe de Siria. En muchos casos, este descuido ha propiciado el expolio de muchos ejemplares, que en la actualidad se encuentran en paradero desconocido o sencillamente han sido destruidos. Desde la perspectiva de Siria, la situación política y social ha propiciado tradicionalmente que el cuidado de los ejemplares manuscritos quedara en manos de las autoridades siempre y cuando los mismos fueran propiedad estatal. De modo general, la atención al patrimonio privado siempre quedó a cargo de excelentes investigadores locales ${ }^{4}$ y del trabajo aislado de algunos estudiosos occidentales ${ }^{5}$.

3. En estas páginas se utilizarán los siguientes grafemas para transliterar el árabe: 'btțğḥhddrzsšșḍtẓ ǵfqklmnhywà (de acuerdo con el orden tradicional del alifato). Las vocales largas se indican con un guión en la parte superior de las mismas. En lo referente a los nombres propios de autores de obras publicadas, se respetará, en su caso, la transcripción que ofrecen de los mismos dichas publicaciones. 4. Concretamente en Alepo debe destacarse el trabajo de Ignace Harfūš (Harfūš, 1914) y Bulus Sbath, que describió en varias publicaciones los diferentes manuscritos que él mismo compró en Egipto, Siria y Líbano y que constituirían la base de la biblioteca de la Fundación Salem (Sbath, 1920, 1926 y 1928). También deben mencionarse aquí a Iskāndar al-Maclūf (Maclūf, 1910a y 1910b) y Anțūn Ğubaylī, que escribió en 1977 un inventario a mano de todos los manuscritos maronitas (Ğubaylī, 1977).

5. Como es el caso concreto de François Nau que, a principios del siglo XX, hizo una primera descripción de la colección de Bulus Sbath (Nau, 1912 y 1913). En la actualidad, debe destacarse el ambicioso 
El examen de los contenidos de algunas de estas colecciones ha deparado numerosas sorpresas a los investigadores. Una de ellas es la presencia de diversas traducciones de obras producidas en Europa, preferente aunque no exclusivamente de temática religiosa, lo cual demuestra que el contacto cultural entre ambos mundos, el otomano y el europeo occidental, siempre se mantuvo vivo en el Levante mediterráneo. Como muestra de ese tipo de literatura de traducción, en el presente trabajo se da noticia de siete códices conservados en tres bibliotecas de Alepo, que contienen traducciones al árabe de varias obras místicas de dos autoras españolas del Siglo de Oro, Teresa de Ávila y María de Ágreda.

\section{DEPÓSITOS DE MANUSCRITOS EN ALEPO (SIRIA)}

En el año 1998, el instituto del Próximo Oriente Antiguo de la Universidad de Barcelona se adhirió al proyecto europeo MANUMED, con el objetivo de examinar los contenidos de algunas bibliotecas privadas de Alepo ${ }^{6}$. En ese contexto, se pudo examinar y determinar cuáles eran los ejemplares conservados en la biblioteca de la comunidad melquita (greco-católica) de esa ciudad. Como continuación de esta iniciativa europea, en el año 2005 comenzó un nuevo proyecto que aún sigue vigente y que tiene como objetivo catalogar todo el material manuscrito de otras dos colecciones: la biblioteca de la Fundación Salem y la de los maronitas, habiendo escogido estos dos fondos de manuscritos por la variedad, el número y el interés de sus ejemplares.

La biblioteca de la comunidad melquita de Alepo ofrece el contenido típico de una biblioteca eclesiástica diseñada con el propósito de formar a su propio clero local. Por consiguiente, en su colección de manuscritos, que contiene 455 ejemplares, se encuentran muchas obras provenientes de su propio ámbito confesional que, por tratarse de una iglesia oriental uniata, es precisamente la Iglesia Católica occidental. Casi todos los ejemplares de este archivo datan de la época otomana (siglos XVI-XIX), como consta en numerosos de sus colofones que aportan la cronología del escriba-copista, del traductor o del autor. El marco temático y cronológico define ya de por sí el interés y valor de esta biblioteca, pues resulta ante todo un testimonio de primer orden para estudiar la situación y desarrollo de la Iglesia melquita en Siria y comprender el serio esfuerzo de formación de su clero en el ámbito de las reformas puestas en marcha por iniciativa de Roma.

Por su parte, el fondo de la Fundación Salem está compuesto casi en su totalidad por los manuscritos comprados por el alepino Bulus Sbath (1887-1945) a partir del año 1912. Estas copias, procedentes en su mayoría de Alepo, además de algunos ejemplares de origen egipcio, libanés y palestino, fueron descritas a principios del siglo XX por el propietario de los ejemplares siguiendo un criterio

proyecto de catalogación digital dirigido por el monje benedictino Columba Stewart (Hill Museum/Manuscript Library, Saint John's University, < http:www.hmml.org $>$ ).

6. Manuscrits de la Méditerranée, sauvegarde et conservation préventive des manuscrits du Proche Orient Méditerranéen. Program MEDA (EMED/Euro-Méditerranéen Heritage) of the European Union ( $\mathrm{n}$. ME8/B7-4100/1B/97/0353-15). 
generalista ${ }^{7}$. La colección Sbath contenía 132 códices arameo-siríacos, árabes, turcos, coptos y armenios datados todos ellos entre los siglos X-XIX. Más tarde, el mismo Bulus Sbath acabó vendiendo 775 ejemplares a la Biblioteca Vaticana; tras su muerte, el patrimonio restante pasó a manos de sus herederos, quienes los donaron a la institución benéfica fundada por Georges y Mathilde Salem, por cuyos nombres se conoce actualmente a dicha colección. A pesar de las vicisitudes que ha sufrido el material conservado en Alepo, los manuscritos de la colección Salem forman una colección que, por su número y su variedad cronológica y temática, puede considerarse una de las más importantes de la República Árabe de Siria. Los 508 ejemplares que siguen conservándose en la biblioteca tocan diferentes temáticas, entre las que destacan la ciencia (astronomía, matemáticas, medicina, farmacopea, alquimia, veterinaria, agronomía y fisiología), la filosofía, la retórica, la poesía, y la teología o espiritualidad tanto cristiana como musulmana ${ }^{8}$.

Por último, la biblioteca de la taifa ${ }^{9}$ maronita de Alepo contiene 1640 manuscritos, aunque sin duda la colección debió ser aún mayor en el pasado. Su característica principal es que se trata también de un depósito típicamente eclesiástico, en el que aproximadamente el $65 \%$ del total de los ejemplares tratan de disciplinas relacionadas con ese entorno. Por consiguiente, la mayoría de los ejemplares están relacionados con el estudio y la lectura de las Escrituras, homilética, teología, filosofía escolástica, derecho canónico, controversias teológicas, devociones, plegarias, hagiografías y espiritualidad, aunque también hay interesantes ejemplares centrados en el estudio de la lengua y la literatura árabe y siríaca, diferentes ciencias, medicina, derecho civil, además de literatura y poesía. Conviene destacar que la mayoría de manuscritos están en árabe, aunque hay una parte significativa en árabe karšūnī o garšūni (es decir, árabe escrito con grafía siríaca ${ }^{10}$ ) y en arameo siríaco.

La presencia de cristianos maronitas en Alepo se remonta probablemente de la Edad Media. Sin embargo, no es hasta finales del siglo XV o comienzos del XVI cuando podemos hablar de una comunidad organizada: probablemente es en este período, que coincidió con el final de la dominación mameluca, cuando se produjo una primera migración masiva de habitantes de la Montaña del Líbano hacia el norte de Siria por causa del aumento de los impuestos y de las hambrunas ${ }^{11}$. El flujo migratorio de maronitas desde el Líbano hacia Alepo aumentó en el primer siglo de dominación otomana (XVI-XVII) tras el aplastamiento de la revuelta del emir druso

7. Sbath, 1920, 1926 y 1928.

8. El examen más reciente del contenido de esta colección de manuscritos ha sido realizado por el autor de este artículo: Río, 2008a.

9. Taifa es el término árabe utilizado para denominar a las diferentes facciones religiosas no musulmanas que existen en Siria. Su significado árabe se adapta perfectamente a la palabra castellana en este contexto. Álvarez, 2013, p. 2.

10. El árabe karšūnī o garšūnī fue utilizado hasta incluso mediados del siglo XX por los cristianos de tradición siríaca con el doble propósito de conservar su propia identidad y evitar la lectura de los textos a aquéllos que no pertenecían a su comunidad. El origen de esta práctica se remonta a la edad media, aunque entre los maronitas se extendió especialmente en la época de dominio otomano. Moukarzel, 2014

11. Salibi, 1959, p. 51. 
Fahr ad-Dīn II, en la que habían participado también los maronitas libaneses ${ }^{12}$. De hecho, los informes que los misioneros occidentales realizaron a comienzos del siglo XVII nos permiten saber que la comunidad maronita de la ciudad contaba en ese momento con unos 4000 miembros, que la mayor parte habitaban en el barrio cristiano de Ğdeydeh y que se caracterizaban por su pobreza ${ }^{13}$. El hecho de que fuera la única confesión católica de la ciudad produjo frecuentes enfrentamientos entre el clero maronita y los misioneros occidentales, pues estos últimos no dudaron en ocupar el único templo católico disponible en la ciudad, para convertirlo en un lugar de culto compartido ${ }^{14}$. En 1634 los maronitas de Alepo reciben por primera vez a un obispo residente, y es en este momento cuando se funda una biblioteca al lado de la residencia episcopal y la antigua iglesia de San Elías. A los antiguos manuscritos, casi todos ellos litúrgicos y de procedencia libanesa, se fueron añadiendo con el tiempo producciones locales de gran calidad, los fondos de los prelados fallecidos y las donaciones de los miembros más eminentes de la comunidad: de esta manera, la biblioteca de los maronitas de Alepo acabó convirtiéndose en una importante colección que destaca por su número y variedad entre las conservadas en la zona ${ }^{15}$.

\section{TRADUCCIONES ÁRABES DE OBRAS DE ESPIRITUALIDAD EUROPEAS}

Es sorprendente el número y la variedad de obras de espiritualidad de la época de la Contrarreforma y del período barroco que pueden encontrarse traducidas al árabe en estas tres bibliotecas cristianas de Alepo. A modo de ejemplo, y refiriéndonos únicamente a las obras de autores españoles, entre los manuscritos hallados se conservan ejemplares de las Meditaciones sobre la Santa Fe (árabe, Ta'ammulāt al-Ğisrì) del jesuita salmantino Luis de la Puente (1554-1624) ${ }^{16}$, el Ejercicio de perfección y virtudes cristianas (conocido en árabe como al-Kamāl al-masịhī, La Perfección cristiana) de Alfonso Rodríguez (m. 1618)17 o los Ejercicios Espirituales (en árabe Riyāḍāt rūḥiyya) de Ignacio de Loyola y de Francisco Javier ${ }^{18}$, todas ellas obras de corte jesuítico traducidas por Pierre Fromage ${ }^{19}$. También se guardan varios ejemplares árabes del Tratado sobre la Vanidad del Mundo del franciscano

\footnotetext{
12. Dib, 1962, vol. II, p. 46.

13. Rabbath-Tournebize, 1905, vol. II, pp. 95-96 y 512-532

14. Ghantuz, 1996, pp. 51-53, 50-64 y 110

15. Río, 2008 b y 2011.

16. Cf. GCAL, IV, p. 224. Algunos ejemplares de esta obra se encuentran en la Biblioteca Salem (núms. 60/840), o en la biblioteca melquita entre otras (núms. 154, 155, 156, 157, 321, 345, 346, 347, 348 y 379 ). 17. Cf. GCAL, IV, p. 230. Algunos ejemplos identificados son los manuscritos Salem 452/1286, Melquita 86-87 y 88/40-I a III y Maronita 328

18. Como los manuscritos 62 y 162 de la Biblioteca Salem, o los 221 y 415 de los melquitas. La difusión de todas estas obras de jesuitas españoles demuestra el éxito que tuvieron, especialmente entre los uniatas de los siglos XVIII y XIX. Ver HMLEM: IV/2, pp. 134-135.

19. Este misionero jesuita, muerto en Alepo en 1740, también tradujo la obra Flos Sanctorum del jesuita español Pedro Ribadeneyra (1526-1611), de la que se encuentra un ejemplar en árabe karšūnī en la biblioteca Maronita de Alepo, en dos volúmenes que datan del siglo XVIII (mss. 299-300).
} 
Diego de Estella (1524-1578), traducido por el mallorquín Rafael Ventanyol20. Todo este tipo de literatura llegó hasta el oriente mediterráneo que estaba bajo dominio otomano por medio de dos canales diferentes pero complementarios.

Como se ha sugerido en el párrafo anterior, los primeros transmisores de obras religiosas occidentales fueron los misioneros europeos enviados a la zona. El papado, justificándose en las actas del tratado de Carlowitz (1699) que permitía la libertad de culto a los ciudadanos europeos que vivían bajo dominio otomano ${ }^{21}$, comenzó a enviar abiertamente grupos de misioneros latinos, los cuales no se limitaron a salvaguardar la fe de sus correligionarios. Protegidos principalmente por Francia, el trabajo de estos religiosos se centró inmediatamente en intentar convertir a los cristianos autóctonos en fieles de la iglesia de Roma, un objetivo que había sido manifiestamente buscado por el papado desde la Edad Media ${ }^{22}$, que había quedado claramente diseñado en el concilio de Trento (desde 1545 hasta 1563) y para el que se habían creado instrumentos eficaces, como la fundación de la Congregación De Propaganda Fide en $1622^{23}$, la creación de colegios para acoger a los alumnos orientales o la construcción de imprentas políglotas ${ }^{24}$. En consecuencia, los misioneros jesuitas, capuchinos, franciscanos y carmelitas enviados por Roma al Levante establecieron su cuartel general en Alepo en 1627, y desde allí se lanzaron a un proselitismo que acabaría afectando profundamente al equilibrio de los cristianos en Siria, además de producir continuas fricciones con el poder civil, a pesar de la ambigua actitud que los sultanes manifestaron respecto a este problema ${ }^{25}$.

Además de las obras difundidas por los misioneros occidentales, deben tenerse en cuenta las versiones al árabe realizadas por los intelectuales maronitas que recibieron su formación en Italia o en España. Esta especial relación de los maronitas con el occidente europeo se debe al hecho de que ésta es la única iglesia oriental que tradicionalmente siempre permaneció unida a Roma, al menos desde la época de las cruzadas, con la consiguiente latinización de sus prácticas y ceremonias ${ }^{26}$. El pacto entre Roma y el clero maronita, sellado en el IV Concilio de Letrán (1215), supuso para esta comunidad un nuevo horizonte de alianzas que le permitió establecer una relación privilegiada con los europeos ${ }^{27}$. En este contexto, el proyecto proselitista diseñado por la Curia romana para el oriente otomano mencionado en el párrafo anterior, hizo que los pontífices fijaran muy pronto su atención en estos cristianos maronitas, a los que se consideró como ejemplo de sumisión y punta

20. GCAL, IV, pp. 184-189. Existen manuscritos de esta obra, titulada en árabe calà I-Ihtiqār abāttil alcālam, en la biblioteca de los melquitas (núm. 89/41-I) o en la maronita, con al menos un curioso ejemplar en karšūnī en tres volúmenes (núms. 305, 306 y 307, del siglo XVIII).

21. RAIEO, I, p. 197

22. Denzinger, 1958, §435; §§694 y 714

23. Masters, 2001, pp. 84-85 y Heyberger, 1994, pp. 225-241, 273-318.

24. La tipografía políglota inaugurada por la nueva congregación de Propaganda Fide (1622) y la imprenta maronita de Alepo, la primera de todo el oriente, sirvieron para abastecer de textos «romanos» a los fieles cristianos del Imperio Otomano.

25. Álvarez, 2013, pp. 14 y ss.

26. Dib, 1962, vol. I, p. 76

27. Moosa, 2005, p. 217 
de lanza para posibles misiones en Levante. La fundación del Colegio Maronita de Roma en 1584 (seguido por otras iniciativas menores en Rávena y Salamanca) facilitaría que muchos alumnos maronitas, gran parte de ellos procedentes de Alepo, se formaran en las disciplinas eclesiásticas siguiendo las formas y contenidos propios del Renacimiento. Esos alumnos acabarían formando una élite fiel que también difundiría la cultura y la espiritualidad europea por Oriente Próximo a través de las traducciones ${ }^{28}$.

\section{MANUSCRITOS ÁRABES EN ALEPO CON OBRAS DE TERESA DE ÁVILA Y MARÍA DE ÁGREDA}

Entre los manuscritos de temática ascética y mística de origen hispano que pueden aún hallarse en Alepo, Ilaman la atención algunos textos de autoría femenina, concretamente los atribuidos a Teresa de Ávila (1515-1582) y a María de Ágreda (1602-1665). El interés que los cristianos de Alepo mostraron por los escritos de estas místicas españolas queda demostrado por la presencia en las mencionadas bibliotecas de diferentes manuscritos con traducciones al árabe de sus obras. El historiador Bernard Heyberger ha apuntado que uno de los métodos más importantes escogidos por los misioneros para atraer a la fe de Roma a los cristianos orientales del Levante otomano fue presentar la espiritualidad occidental sirviéndose de la literatura espiritual. Muy frecuentemente, eran las mujeres las primeras en abrazar el uniatismo o incluso el rito latino. Este tipo de literatura de autoría femenina pudo estar destinada en un principio a estas conversas de las comunidades cristianas orientales ${ }^{29}$.

\section{a. Obras de Teresa de Ávila}

Yūsuf ibn Ğirgis al-Bānī (también conocido con su nombre italianizado Giuseppe Banete o el latinizado loannes Banes) era un maronita de Alepo que había sido estudiante en Roma y luego profesor de lengua árabe y siríaca en el Colegio de Propaganda Fide de la misma ciudad durante el último tercio del siglo XVII. Durante el año 1719 tradujo dos obras de Teresa de Ávila, sirviéndose para ello de una traducción italiana no identificada de las mismas: nos referimos a Las Moradas del Castillo Interior (Qalacat an-nafs) y del Camino de Perfección (Ṭaríq al-Kamāl). Probablemente, Yūsuf, que es conocido por sus versiones árabes de otras de origen europeo, trabajó siguiendo las indicaciones de una de las figuras más eminentes del Alepo otomano del siglo XVIII, el arzobispo maronita Ğarmānūs Farhāt (m. 1724), uno de los reconocidos precursores del renacimiento cultural árabe del siglo XIX ${ }^{30}$. De la versión árabe de Las Moradas realizada por Yūsuf ibn Ğirgis al-Bānī se guarda al menos un ejemplar en la biblioteca de los melquitas de Alepo: nos referimos al manuscrito 92/44 de dicha colección, un volumen que data probablemente

28. Un exhaustivo listado de autores maronitas procedentes de Europa en GCAL, IV, pp. 184-189.

29. Heyberger, 1994, pp. 149-153.

30. GCAL, III, p. 386. 
de finales del siglo XVIII con 60 folios en papel $(215 \times 160 \mathrm{~mm})$ encuadernado en cuero sobre cartón, que se conserva en un discreto estado de conservación. Aunque el texto ha sido copiado a dos tintas, roja y negra, tanto el tipo de caligrafía (ru$\left.q^{c} a\right)$ como la factura del texto denotan que no es una realización de calidad, como puede verse en otros ejemplares de este tipo. En el reverso del folio 2 aparece tanto el nombre de la obra como el del traductor.

Otra obra perteneciente a este grupo es una colección de textos divididos en trece capítulos, titulada Libro de la belleza provechosa para el alma alegre (Kitāb al-ğumal al-mufída lin-nafs as-sacīda). Este compendio es el producto de una selección y traducción al árabe realizada por un misionero carmelita que probablemente se llamaba Hieronymus y que utilizó a tal efecto una traducción al italiano del original en castellano. De esta obra se conservan en Alepo al menos tres ejemplares: uno en la biblioteca Salem (el manuscrito árabe 275/1081), ${ }^{31}$ otro en la colección melquita (núm. 308/285), titulado simplemente Meditaciones de santa Teresa (en árabe, Ta'ammulāt al-qiddīsa Tirāzìya) y un tercero en la biblioteca de los maronitas (núm. 436). Otras copias se encuentran en la Biblioteca Vaticana (un volumen, el antiguo Sbath 355 , que fue vendido por su propietario a esta institución) y al menos un manuscrito en territorio libanés ${ }^{32}$.

El manuscrito conservado en la biblioteca de la fundación Salem de Alepo es un volumen que por su factura parece datar del siglo XIX (sobre la encuadernación pueden leerse dos fechas 1824 y 1829). Aunque no aparece el nombre del copista, puede observarse que la letra, en caligrafía árabe nashī a dos tintas, ha sido cuidada con esmero. El manuscrito se encuentra en buen estado de conservación. mide 146×105 mm, incluye 132 folios sin numerar y está encuadernado en cartón. En el folio 4a puede leerse en árabe la referencia al misionero carmelita autor de la traducción. Por su parte, el núm. 308 de la colección melquita, ostenta el título antes mencionado en el reverso del folio 1. Esta copia, que se remonta al siglo XVIII se encuentra en mal estado de conservación. De hecho conserva únicamente 20 folios sin numerar de 133×67 mm que han sido encuadernados en época más moderna con unas tapas de plástico. El copista de la misma no aparece identificado.

El manuscrito 436 de los maronitas, un volumen que contiene diferentes obras de espiritualidad, incluye en los folios 3b-29a el mismo contenido, aunque con un título diferente: Meditaciones del alma respecto a Dios altísimo, cuya autora es la madre y virgen santa Teresa. Las pronunció en diferentes días después de la santa comunión, en 17 capítulos o meditaciones. El códice en cuestión, de 100x95 mm. es un ejemplar con 71 folios, pobremente encuadernado en cartón, y que por sus características probablemente data del siglo XVIII. Como puede comprobarse en la imagen siguiente, su caligrafía a dos tintas, típicamente nashī otomana, ha sido cuidada con esmero por el copista de la obra. 


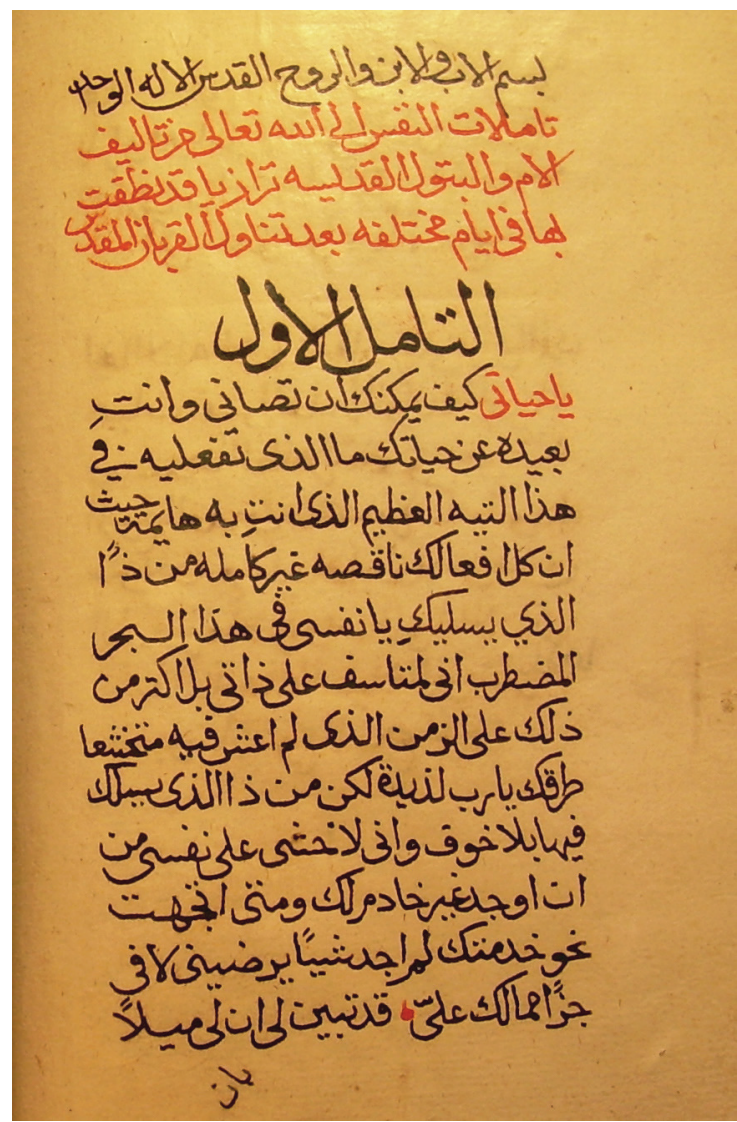

Folio 3b del manuscrito 436 perteneciente a la taifa maronita de Alepo con 17 Meditaciones de Teresa de Jesús. (Fotografía, F. del Río)

Por último, debe mencionarse también el Libro de las Siete meditaciones sobre el Padre Nuestro para los siete días de la semana, normalmente atribuido a Teresa de Ávila, y que no debe confundirse con el Camino de Perfección o Libro del Paternoster. La obra a la que aquí nos referimos fue escrita en realidad por un autor carmelita anónimo que vivió en el siglo XVI aunque tradicionalmente se suponía compuesta por la santa abulense ya que solía añadirse a las ediciones del corpus de escritos de esta autora ${ }^{33}$. De las dos copias que hay en Alepo $^{34}$, la primera se encuentra en la biblioteca de la Fundación Salem, numerada con 381/1205: un cuaderno de 30 folios ( $125 \times 90 \mathrm{~mm}$.) que fue terminado de copiar el 21 de enero de 1823 (folio 30b) y que se titula en árabe Siete meditaciones sobre el Padre Nuestro,

33. Obras de Santa Teresa de Jesús, edición completísima, tomo I, Madrid, Nicolás de Castro Palomino 1851, Prólogo; Fuente, 1877, pp. 538-545.

34. Fuera de Alepo existe otra identificada en el fondo de la Biblioteca Vaticana, el ms. Ar. 1286, del año 1724. Ver GCAL, IV, p. 249. 
organizadas para los siete días de la semana (folio 1b). El manuscrito, escrito a dos tintas, fue cuidadosamente escrito en caligrafía nashī por un copista desconocido. La segunda copia se conserva en la biblioteca melquita con el número 414, y se titula Siete meditaciones sobre la oración del Señor (Sabª ta'ammulāt calà aș-ṣalwa ar-rabāniyya). Fue compuesta por la santa virgen Teresa, madre de los frailes Carmelitas descalzos y fundadora de sus monjas. Está distribuida en siete viernes. Fue traducida por un fraile carmelita del italiano [sic] al árabe (folio 2b).

El volumen, que probablemente data del siglo XVIII contiene 89 folios (155X100 $\mathrm{mm}$ ) y está encuadernado en cartón forrado de cuero. El copista, también desconocido, utilizó un sistema semejante al del ejemplar anterior; de hecho, este texto tiene unas características muy semejantes a la copia de la fundación Salem, tanto en el tipo de caligrafía como en el uso de dos tintas para destacar la puntuación.

\section{b. La Mística Ciudad de Dios de María de Ágreda}

En la biblioteca de la taifa de los maronitas de Alepo se encuentra una copia manuscrita en árabe de la obra Mística Ciudad de Dios, de la franciscana María de Ágreda (1602-1665), que probablemente fue una de las figuras más emblemáticas de la espiritualidad del barroco español. Las circunstancias por las que pasó esta obra, descrita por Bossuet como una «impía impertinencia» ${ }^{35}$, hacen aún más interesante el hallazgo. El libro de María Coronel y Arana (María de Jesús del convento de Ágreda), descendiente a la vez de conversos y de hidalgos vasco-navarros, ya había sido condenado por la Inquisición romana en 1681 aunque se siguió permitiendo su lectura en España gracias a la intervención del rey Carlos II. Sin embargo en 1696 el recoleto Croset tradujo y publicó en Marsella la primera parte del mencionado texto: su difusión en Francia provocó una rápida y contundente respuesta en la Sorbona. Tras un estudio en el que participaron 132 doctores reunidos en 32 sesiones se acabó condenando la Mística Ciudad de Dios por escotista, describiéndola como un compendio de afirmaciones escandalosas e imaginarias que se basaban en falsas revelaciones. La polémica acabó convirtiéndose en la práctica en un conflicto entre España y Francia y no se resolvió hasta al menos mediados del siglo XVIII'36.

Como podrá comprobarse, la traducción árabe de este libro debió realizarse en alguna de las provincias orientales del Imperio Otomano, probablemente en Damasco o en Jerusalén en una fecha anterior al año 1724, es decir, cuando la polémica acerca de la ortodoxia o no del escrito aún no estaba zanjada. El autor fue un franciscano de origen mallorquín llamado Rafael Ventayol, uno de los ilustres arabistas españoles surgidos durante los siglos XVII y XVIII. Nacido en Alcudia (MaIlorca), Ventayol ingresó en la orden franciscana y luego fue destinado al Levante

35. Bossuet acusó a María de Ágreda de filo-escotista y de utilizar un lenguaje indecente. Ver Hemey d'Auberive, Oeuvres de Bossuet, pp. 637-640.

36. Campbell, 1913. 
otomano. Desde 1679 hasta 1684 dirigió la escuela de árabe de Damasco ${ }^{37}$ y tras esa actividad fue destinado a Jerusalén, donde murió durante la primera mitad del siglo XVIII38. Además de su labor como misionero (fue procurador general de Tierra Santa y guardián del convento de Belén), trabajó al servicio de los soberanos de España, Francia y Portugal, que le encargaron delicadas misiones diplomáticas ante la Sublime Puerta de Constantinopla ${ }^{39}$.

Además de esta actividad, Rafael Ventayol se dedicó también a la traducción de obras religiosas destinadas a los cristianos de Tierra Santa. De toda esta labor únicamente se han conservado dos trabajos: 1) su versión árabe de la obra ascética Libro de la Vanidad del Mundo del franciscano Diego de Estella (m. 1578), el Kitāb abātil al-cālam mencionado más arriba, del que se hicieron dos ediciones en Tierra Santa, en 1739 y $1860^{40}$ y 2) la aquí mencionada Mística Ciudad de Dios (titulada en árabe Madinnat Allāh as-sirriyya wa-căğibat qūwat Allāh al-kulliyya wa luğğat annicma as-sāmiya as-sanniyya), que nunca fue publicada y de la que se conservan muy pocas copias manuscritas ${ }^{41}$. La peculiaridad de la copia procedente de la biblioteca maronita de Alepo es que está escrita en árabe pero en el ya mencionado sistema karšūnī o garšūnī, lo cual la convierte en un ejemplar único en su género. La copia de los maronitas alepinos se encuentra dividida en dos volúmenes (mss. 297 y 298), realizados con esmero por un copista maronita anónimo probablemente de Alepo. La escritura, como se ha indicado más arriba es arameo-siríaca occidental (ser o), la caligrafía utilizada por los maronitas para sus escritos en siríaco o en karšūnī. La disposición del texto en ambos ejemplares es la misma: 25 líneas de media por página, en tinta negra y roja (esta última para los títulos y la puntuación), sirviéndose de una falsilla o plantilla para conservar la uniformidad en el espaciado y la horizontalidad. Los volúmenes están encuadernados en cartón forrado en cuero y se conservan en buen estado de conservación.

Como aparece señalado en las notas del folio 264a (el mismo en ambos manuscritos) la obra formó parte de la biblioteca personal del famoso arzobispo maronita de Alepo Ğarmānūs Farhāt hasta que tras su muerte, acaecida en el año 1732, pasó a formar parte de la colección de la «lglesia (maronita) de San Elías» por voluntad del propietario. El volumen primero incluye 25 capítulos (índice, folios 13a14a), mientras que el segundo contiene 28 (folios 4b-6a). El nombre del traductor, Rafael Ventayol aparece mencionado en el folio $4 \mathrm{~b}$ del primer volumen, que aquí aparece reproducido. Ésta es la traducción de las 15 primeras líneas, incluyendo la doxología inicial.

37. Sobre esta institución y la presencia de profesores y alumnos españoles en ella durante el siglo XVII, ver Lourido, 2006, pp. 105-251

38. Lourido, 2005, pp. 90-95.

39. Piferrer, Nobiliario de los reinos y señoríos de España, p. 31

40. Se conservan varias copias en Alepo, entre ellas los manuscritos 305, 306 y 307 de la biblioteca maronita (en karshuni), fechados en el siglo XVIII, y el códice árabe 89 [41/1] de la biblioteca melquita, de finales del XVIII o comienzos del XIX. Ver GCAL, IV, pp. 184-185; Bueno, 2010, p. 34.

41. Concretamente 2 ejemplares en la Biblioteca Oriental de Beirut, 1 en el Cairo y 3 en Alepo: además de la copia aquí presentada, existe otra en la biblioteca de los franciscanos de esta ciudad y otra más en paradero desconocido. GCAL, IV, p. 184. 
En el nombre del Padre, del Hijo y del Espíritu Santo, único Dios, amén. Éste es el libro Mística Ciudad de Dios, Portento de la Omnipotencia Divina y Espejo de la Sublime y Elevada Gracia (Madīnat Allāh as-sirriyya wa-că̄ībat qūwat Allāh al-kulliyya wa luğğat an-nicma as-sāmiya as-sanniyya). Contiene la historia de la divina Virgen María, Madre de Dios, nuestra Reina y Señora. La Virgen, nuestra Señora [lit. «Su Señora»] fue preservada de mácula, sin el defecto del pecado de Eva, y es intercesora de la Gracia. El tratado [acerca de] esta portentosa historia y este magnífico estado se lo mostró la Virgen en los últimos tiempos y se lo dio a conocer a su sierva la honorada monja María esclava de Jesús, superiora del convento llamado de la Inmaculada Concepción de la Virgen en la villa de Ágreda, situada en la demarcación de la ciudad de Burgos, que está adscrito a la observancia de la regla de nuestro padre San Francisco. [Ésta obra] es una luz nueva para el mundo, y alegría y regocijo para la Iglesia Católica. La tradujo de la lengua española a la lengua árabe el padre Rafael, apellidado Ventayol (Wāntiyūs, sic), de los frailes de San Francisco llamados sirvientes (?), es decir «custodios», que desde tiempo moran en Jerusalén.

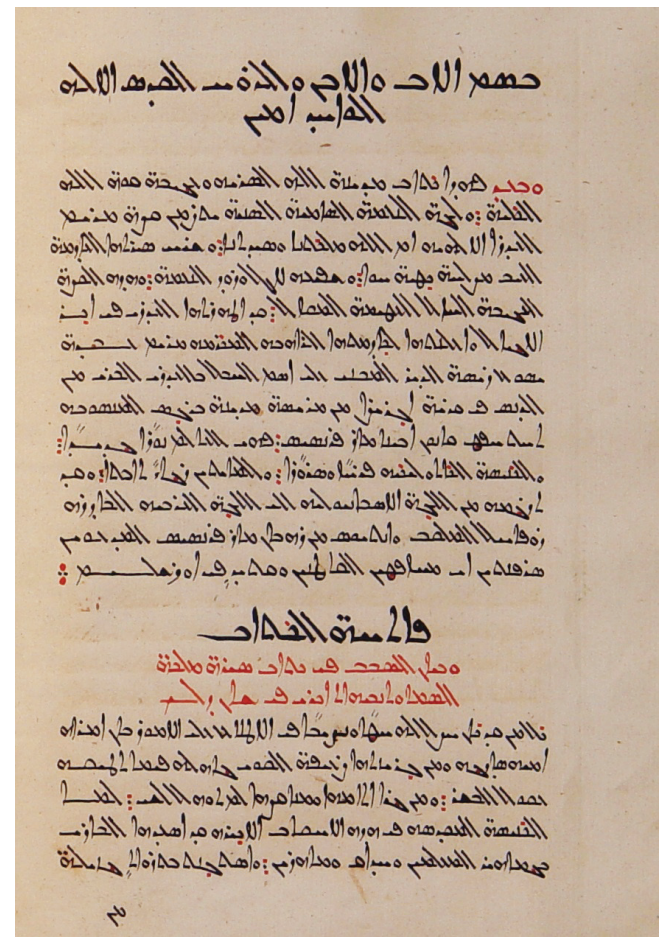

Folio 4b del manuscrito 297 perteneciente a la taifa maronita de Alepo con la obra Mística Ciudad de Dios, de María de Ágreda

(Fotografía, F. del Río)

La traducción de obras de espiritualidad europeas por parte de las comunidades cristianas que habitaban en las provincias árabes del Imperio Otomano revelan 
el aliento de estos grupos religiosos que luchaban por mantener vivas sus creencias y costumbres minoritarias en un contexto de tolerancia tutelada como la que ofrecía la administración musulmana turca y de la nada fácil convivencia con sus propios correligionarios cristianos de otras taifas confesionales. Una de las características de la vida cultural de esos cristianos fue el interés que mostraron por las obras teológicas y espirituales producidas en el occidente europeo, un interés que se concretó en la traducción sistemática de muchos trabajos de diferente índole, entre los que destacan aquéllos relacionados con la producción mística de algunas autoras españolas aquí presentadas.

Este tipo de traducciones, realizadas en Alepo y otros lugares del Levante mediterráneo durante la época otomana, dan fe de un cultivo pujante de la lengua árabe por parte de las comunidades cristianas, precisamente en una época comúnmente considerada de decadencia, si no de completa latencia. Ese uso del árabe como lengua culta para el uso eclesiástico estuvo acompañado de un cultivo de esa misma lengua como instrumento de creación de obras profanas en géneros como la poesía, la ciencia, la historia y la misma gramática. Este rearme espiritual e intelectual de las comunidades árabes cristianas gracias a la influencia occidental, y el desarrollo de la traducción al árabe serán los precedentes de lo que se conoce comúnmente como época del renacimiento de esta lengua durante el siglo XIX. El descubrimiento de nuevas obras traducidas como las que aquí se han presentado, permite ilustrar aún más si cabe la importante aportación de los autores que pertenecieron a este ámbito confesional.

\section{BIBLIOGRAFÍA}

Álvarez Suárez, Alejandra, Comunidades no musulmanas en un entorno musulmán. La pervivencia del modelo otomano en la actual Siria, Madrid, Cantarabia, 2013.

Bueno García, Antonio, «Ética y estética de la traducción monástica. Los traductores y lingüistas franciscanos españoles del árabe y del hebreo», Traslationes, 2, 2010, pp. 25-38.

Campbell, Thomas, «Ágreda, María de», en Charles G. Herbermann et al. (eds.), The Catholic Encyclopedia: An International Work of Reference on the Constitution, Doctrine, Discipline, and History of the Catholic Church, vol. 1, Nueva York, Robert Appleton Company, 1913, pp. 229-230.

Denzinger, Heinrich Joseph, Enchiridion Symbolorum, Definitionum et Declarationum de Rebus Fidei et Morum, Friburgo de Brisgovia, Herder, 1958.

Dib, Pierre, Histoire de l'Église Maronite, Beirut, La Sagesse, 1962, 3 vols.

Fuente, Vicente de la (ed.), Escritos de la Santa Madre Teresa de Jesús, Madrid, BAE, 1877.

Ghantuz, Mariam de, I maroniti d'Aleppo nel XVII secolo. Patrimonio Culturale Arabo-Cristiano 2, Turín, Silvio Zamorani Editore, 1996. 
GCAL, Graf, Georg, Geschichte der christlichen-arabischen Literatur, Roma, Biblioteca Apostólica, 1949-1951, 4 vols. + índices.

Ğubaylī, Anțūn, Fihrist al-mahțūțāt lil-kanīsa al-mārūnīyya [Inventario de los manuscritos de la Iglesia Maronita], Alepo, 1977 (copia manuscrita).

Harfūš, Ignace, «Maktabat țāiffatinā al-mārūniyya fĩ madīnat Ḥalab» [La biblioteca de nuestra taifa maronita en la ciudad de Alepo], Al-Mašriq, 17, 1914, pp. 2129, 89-101, 354-363, 599-608 y 763-764.

Hemey d'Auberive, Philibert Nicolas (ed.), Oeuvres de Bossuet, évèque de meaux, revues sur les manuscrits originaux, et les éditions les plus corrects, Volumen XXX, Paris, Imprimerie de J. A. Lebel, 1817.

Heyberger, Bernard, Les chrétiens du Proche-Orient au temps de la réforme catholique (Syrie, Liban, Palestine XVI-XVII s.), Roma, École Française, 1994.

HMLEM, Nasrallah, Joseph, Histoire du mouvement littéraire dans l'Église Melchite du Ve au Xe siècle, Louvain-Paris, Peeters, 1979-1989, 4 vols.

Lourido Díaz, Ramón (ed.), Fr. Bernardino González O.F.M. (c. 1665-c. 1735). Intérprete Arábico, epítome de gramática arábiga [Obras Manuscritas], Madrid, Real Academia de la Historia/Ministerio de Asuntos Exteriores, 2005, 2 vols.

Lourido Díaz, Ramón, El estudio del árabe entre los franciscanos españoles en Tierra Santa. Siglos XVII-XIX, Madrid, Ed. Cisneros, 2006.

Mac|ūf, Iskāndar al-, «Makātib Ḥalab wa-Dimašq» [Bibliotecas de Alepo y Damasco], al-Hilāl, 19, 1910a, pp. 491-493.

Maclūf, Iskāndar al-, «Makātib Ḥalab» [Bibliotecas de Alepo], an-Nicma, 2, 1910b, pp. 299, 404, 591.

Masters, Bruce, Christians and Jews in the Ottoman Arabic Word: The Roots of Sectarianism, Cambridge, Cambridge University Press, 2001.

Moosa, Mati, The Maronites in History, Piscataway, Gorgias Press, 2005.

Moukarzel, Joseph, «Maronite Garshuni Texts: On Their Evolution, Characteristics, and Function», Hugoye, 17/2, 2014, pp. 237-262.

Nau, François, «Catalogue sommaire des manuscrits du P. A. Sbath», Revue de I'Orient Chrétien, 7/17, 1912, pp. 280-285.

Nau, François, «Catalogue sommaire des manuscrits du P. A. Sbath», Revue de l'Orient Chrétien, 8/18, 1913, pp. 245-246.

Piferrer, Francisco, Nobiliario de los reinos y señoríos de España, vol. IV, Madrid, Imprenta de Menuesa, 1858.

Rabbath, Antoine y Françoi Tournebize, Documents Inédits pour servir a l'Histoire du Christianisme en Orient, Paris, Picard et Fils, 1905-1910, 2 vols. 
RAIEO, Nouradounghian, Gabriel Effendi, Recueil d'Actes Internationaux de l'Empire Ottoman, Paris, F. Pichon, 1897-1903, 4 vols.

Del Río Sánchez, Francisco, Manuscrits de la Fondation Georges et Mathilde Salem (Alep, Syrie), Wiesbaden, Reichert Verlag, 2008a.

Del Río Sánchez, Francisco, Manuscrits Syriaques conservés dans la Bibliothèque des Maronites d'Alep (Syrie), Piscataway, NJ, Gorgias Press, 2008b.

Del Río Sánchez, Francisco, Manuscrits en Arabe Karshouni conservés dans la Bibliothèque des Maronites d'Alep (Syrie), Piscataway, NJ, Gorgias Press, 2011.

Salibi, Kamal S., Maronite historians of medieval Lebanon, Beirut, American University, 1959.

Santa Teresa de Jesús, Obras de Santa Teresa de Jesús, edición completísima, Madrid, Nicolás de Castro Palomino, 1851.

Sbath, Paul, «Manuscrits orientaux de la Bibliothèque Asbat», Revue de l'Orient Chrétien, 2/22, 1920-1921, pp. 194-205.

Sbath, Paul, «1500 manuscrits scientifiques et littéraires très anciens, en arabe et en syriaque», Bulletin de l'Institut Égyptien, VIII, 1926, pp. 21-43.

Sbath, Paul, Bibliothèque de Manuscrits Paul Sbath, Prête Syrien d'Alep, Cairo, H. Freidrich et Co., 1928-1934, 3 vols. 
